\title{
Regulation of mRNA gene expression of members of the NF-кB transcription factor gene family by angiotensin II and relaxin 2 in normal and cancer prostate cell lines
}

\author{
KAMILA DOMIŃSKA ${ }^{1}$, KAROLINA KOWALSKA ${ }^{1}$, ZUZANNA ELŻBIETA MATYSIAK ${ }^{1}$, ELŻBIETA PŁUCIENNIK ${ }^{2}$, \\ TOMASZ OCHĘDALSKI ${ }^{1}$ and AGNIESZKA WANDA PIASTOWSKA-CIESIELSKA ${ }^{1,3}$
}

Departments of ${ }^{1}$ Comparative Endocrinology and ${ }^{2}$ Molecular Carcinogenesis; ${ }^{3}$ Laboratory of Cell

Cultures and Genomic Analysis, Medical University of Lodz, Lodz 90-752, Poland

Received August 26, 2016; Accepted February 24, 2017

DOI: $10.3892 / \mathrm{mmr} .2017 .6514$

\begin{abstract}
An increasing number of researchers are focusing on the influence of local peptide hormones such as angiotensin II (Ang II) and relaxin 2 (RLN2) in the regulation of inflammation and carcinogenesis. The interaction between the renin-angiotensin system (RAS) and relaxin family peptide system (RFPS) is known to influence the proliferation, adhesion and migration of normal and cancer prostate cell lines. The aim of the present study was to evaluate changes in the expression of nuclear factor- $\kappa \mathrm{B}$ subunit 1 (NFKB1), nuclear factor- $\kappa \mathrm{B}$ subunit 2 (NFKB2), REL proto-oncogene nuclear factor- $\kappa$ B p65 subunit (REL), RELA proto-oncogene nuclear factor- $\kappa \mathrm{B}$ subunit (RELA) and RELB proto-oncogene nuclear factor $-\kappa B$ subunit (RELB) mRNA caused by Ang II and RLN2. The members of NF-kB family are involved in many processes associated with cancer development and metastasis. Reverse transcription-quantitative polymerase chain reaction analysis identified that both peptide hormones have an influence on the relative expression of nuclear factor- $\kappa$ B. Following treatment with either peptide, NFKB1 expression was downregulated in all prostate cancer cell lines (LNCaP, DU-145 and PC3), but not in normal epithelial cells (PNT1A). Conversely, RELB mRNA was enhanced only in non-cancerous prostate cells. RELA expression was strongly stimulated in the most aggressive cell line, whereas REL mRNA was unchanged. In many cases, the effect was strictly dependent on the cell line and/or the type of peptide: Ang II increased expression of both RELA and REL genes in the
\end{abstract}

Correspondence to: Dr Kamila Domińska, Department of Comparative Endocrinology, Medical University of Lodz, Zeligowskiego 7/9, 90-752 Lodz, Poland

E-mail: kamila.dominska@umed.lodz.pl

Key words: angiotensin, relaxin, prostate, nuclear factor- $\kappa \mathrm{B}$ subunit 1 , nuclear factor- $\kappa \mathrm{B}$ subunit 2 , REL proto-oncogene nuclear factor- $\kappa \mathrm{B}$ subunit, RELA proto-oncogene nuclear factor- $\kappa \mathrm{B}$ subunit, RELB proto-oncogene nuclear factor- $\kappa \mathrm{B}$ subunit, androgen receptor androgen-dependent cell line while RLN2 enhanced NFKB2 and RELA mRNA in androgen-independent cells (DU-145). Further research is needed to understand the regulation of $\mathrm{NF}-\kappa \mathrm{B}$ family members by key renin-angiotensin system and RFPS peptides in prostate cancer cells; however, prostate carcinogenesis appears to be influenced by the balance between the cross-regulation of nuclear factor- $\kappa \mathrm{B}(N F-\kappa B)$ and androgen receptor pathways by Ang II and relaxin 2 .

\section{Introduction}

Angiotensin II (Ang II) is an octapeptide hormone best known for its role in the maintenance of blood pressure and water-electrolyte balance, while the most commonly-known function of relaxin 2 (RLN2) is its role in pregnancy and parturition. However, many other features of these peptide hormones have been noted at the tissue level. During the last few decades, an increasing number of studies have implicated Ang II and relaxin 2 as well as other peptide hormones in cancer initiation, progression and metastasis. For example, strong expression has been observed of relaxin 2, the relaxin receptor RXFP1/LGR7, Ang II and angiotensin receptor type 1 in tumor tissue compared to normal prostate or breast tissue (1-4). Recent studies of the authors have analyzed the interaction between the rennin-angiotensin system (RAS) and the relaxin family peptide system (RFPS), and their effects on various aspects of prostate cancer development. The findings suggest that the two investigated systems are functionally linked and have an impact on cell growth and proliferation by their partially overlapping signal transduction pathways. It has been reported that Ang II and relaxin 2 can serve an important role in increasing the aggressiveness of prostate tumors by upregulating BIRC5 expression and gelatinase $\mathrm{A}$ and $\mathrm{B}$ secretion. In addition, previous results of the authors suggest that both peptide hormones are implicated in the transition from the androgen-dependent to the androgen-independent phenotype in prostate cancer by modulation of the expression of androgen receptors (AR) $(5,6)$.

The present study demonstrates that Ang II and relaxin 2 alter the mRNA expression of $N F-\kappa B$ family members in normal and cancer prostate cell lines. The NF- $\mathrm{B}$ family 
consists of transcription factors [nuclear factor- $\kappa \mathrm{B}$ subunit 1 $(\mathrm{NF}-\kappa \mathrm{B} 1)$ and nuclear factor- $\kappa \mathrm{B}$ subunit $2(\mathrm{NF}-\kappa \mathrm{B} 2), \mathrm{REL}$ proto-oncogene nuclear factor- $\kappa \mathrm{B}$ subunit (REL), RELA nuclear factor- $\kappa \mathrm{B}$ subunit (RelA), RELB proto-oncogene nuclear factor- $\kappa \mathrm{B}$ subunit (RelB)] that serve critical roles in cell proliferation and differentiation, regulation of survival and apoptosis. However, the biological significance of $\mathrm{NF}-\kappa \mathrm{B}$ activation in carcinoma tissues remains unclear. Several researchers have reported constitutive activation of $\mathrm{NF}-\kappa \mathrm{B}$ in tumors such as ovarian cancer, breast cancer, pancreatic cancer and prostate cancer. Over-expression of NF- $\kappa \mathrm{B}$ in the nucleus of prostate cancer cells is associated with chemoresistance, more aggressive cancer phenotypes and metastatic spread. In addition, studies have indicated that activation of $\mathrm{NF}-\kappa \mathrm{B}$ signaling promotes castrate-resistant growth of prostate tumors (7-10).

These studies are a continuation of earlier research $(5,6)$ intended to elucidate the mechanisms of tumorigenesis and prostate cancer progression associated with RAS and RFPS.

\section{Materials and methods}

Reagents. Ang II (H-1705) and relaxin 2 (H-6784) were obtained from Bachem (Bubendorf, Switzerland). The octapeptide Ang II is a major biologically active component of the RAS. Relaxin 2, the 6-kDa heterodimeric polypeptide hormone, is a member of the RFPS. The pleiotropic effects of both peptides are determined by the signaling pathway profile activated in target cells. For all experiments, peptides were used at a final concentration of $10^{-8} \mathrm{M}$. This concentration was selected on the basis of earlier research work $(5,6)$. Unless otherwise specified, the medium and other culture supplements were purchased from Gibco; Thermo Fisher Scientific, Inc. (Waltham, MA, USA).

Cell lines and culture conditions. Prostate cancer cell lines (LNCaP, DU-145, PC3) were obtained from the American Type Culture Collection (Manassas, VA, USA), while immortalized, normal prostate epithelial PNT1A cells were obtained from the European Collection of Authenticated Cell Cultures (Salisbury, UK). All 4 stable cell lines were authenticated by short-tandem repeat DNA profiling by the LGC Standards Cell Line Authentication Service (Koeln, Germany).

The LNCaP cells, identified in a relatively slow growing and weakly tumorigenic prostate cancer, were isolated from a supraclavicular lymph node metastasis. The PC3 cells were characterized by low diversity and high invasiveness (stage IV) and were established from bone metastases. The androgen-independent DU-145 cells were derived from brain metastases, and represent an intermediate model between the LNCaP and PC3 cells (11). The PNT1A cells were established by immortalization of normal adult prostatic epithelial cells by transfection with a plasmid containing the SV40 genome with a defective replication origin. This stable cell line represents a good model to study of initial steps leading to transformation of the prostate gland (12). The cells were grown in a classical two-dimensional (2D) cell culture system using plates or flasks and Advanced RPMI-1640 medium supplemented with 5\% FBS, 2 mM L-glutamine, $1 \mathrm{mM}$ sodium pyruvate and antibiotics. The incubator was maintained at an optimal temperature $\left(37^{\circ} \mathrm{C}\right)$, humidity $(95 \%)$ and other conditions, such as the carbon dioxide $\left(5 \% \mathrm{CO}_{2}\right)$ of the atmosphere inside needed to grow human cells. Cells were harvested with $0.25 \%$ trypsin/EDTA. The cells were passaged at least twice after thawing from liquid nitrogen. Further experiments used cells with a passage number between 15 and 35 .

Reverse transcription-quantitative polymerase chain reaction $(R T-q P C R)$. The prostate cells were exposed to Ang II, relaxin 2 or a combination of both for $48 \mathrm{~h}$. Total RNA was extracted from the cells using TRIzol reagent (Thermo Fisher Scientific, Inc.) and purified with the standard phenol: chloroform method. The concentration of recovered RNA and its purity was determined by BioDrop $\mu$ LITE: A UV/Vis spectrophotometer designed for micro-volume measurements (Isogen Life Science B.V.,Utrecht, Netherlands). mRNA expression was evaluated by RT-qPCR, using a LightCycler 480 real-time PCR system (Roche Diagnostics, Basel, Switzerland) and EvaGreen PCR master mix (IMMUNIQ, Zory, Poland). Reverse transcriptase synthesis of cDNA was performed on a $10 \mu \mathrm{g}$ total mass of RNA in a final volume of $50 \mu \mathrm{l}$ using an oligo(dT) 15 Primer Random Hexamer primer and ImProm-II ${ }^{\mathrm{TM}}$ Reverse Transcription System (Promega Corporation, Madison, WI, USA), as described previously (13). Amplification reactions were performed in a final volume of $20 \mu \mathrm{l}$, containing $2 \mu \mathrm{l}$ cDNA. Detection temperature was above non-specific/ primer-dimer melting temperature. Primer sequences were designed using PrimerQuest Tool (www.idtdna.com/primerquest/home/index) or Primer3 Input (http://bioinfo.ut.ee/ primer3-0.4.0/) and checked for specificity using BLAST (https://blast.ncbi.nlm.nih.gov/). All primers were designed to be intron-spanning to avoid amplifying genomic DNA. Detection temperature was above unspecific/primer-dimer melting temperature. Sequences of primers, annealing and detection temperatures are presented in Table I. H3F3A and RPLPO were included as housekeeping gene controls to correct for identical amount of cDNA in all qPCR reactions. The Universal Human Reference RNA (Stratagene; Agilent Technologies, Inc., Santa Clara, CA, USA), composed of total RNA from 10 human cell lines, was used as a calibrator. The primers and reaction conditions are presented in Table I. All the reactions were run in duplicate, including no-template controls. The relative gene expression level was calculated according to the Roche algorithm (14).

Statistical analysis. The results are presented as mean \pm standard error of the mean of at least three independent samples. The measurements were analyzed using one-way analysis of variance with Dunnett's multiple comparison test. $\mathrm{P}<0.05$ was considered to indicate a statistically significant difference.

\section{Results}

Influence of Ang II and relaxin 2 on $m R N A$ expression of members of the NF- $k B$ transcription factor gene family in prostate cancer cell lines. The results of the RT-qPCR identified relative NFKB1 expression to be almost double the expression in the PC3 (1.05 \pm 0.19 ; Fig. 2A, right panel) and DU-145 $(1.05 \pm 0.16$; Fig. 2A, left panel) cell lines than in LNCaP cells (0.55 \pm 0.13 ; Fig. 1A). Similarly, androgen-dependent LNCaP 
Table I. Reverse transcription-quantitative polymerase chain reaction primers and reaction conditions.

\begin{tabular}{|c|c|c|c|}
\hline $\begin{array}{l}\text { Gene } \\
\text { name }\end{array}$ & $\begin{array}{c}\text { Gene primer } \\
\text { sequence }\left(5^{\prime}-3^{\prime}\right)\end{array}$ & $\begin{array}{c}\text { Annealing } \\
\text { temperature }\left({ }^{\circ} \mathrm{C}\right)\end{array}$ & $\begin{array}{l}\text { Detection } \\
\text { temperature }\left({ }^{\circ} \mathrm{C}\right)\end{array}$ \\
\hline H3F3A & $\begin{array}{l}\text { Forward: 5-AGGACTTTAAAACAGATCTGCGCTTCCAGAG-3' } \\
\text { Reverse: 5-ACCAGATAGGCCTCACTTGCCTCCTGC-3' }\end{array}$ & 65 & 72 \\
\hline RPLPO & $\begin{array}{l}\text { Forward: 5- ACGGATTACACCTTCCCACTTGCTAAAAGGTC-3' } \\
\text { Reverse: 5- AGCCACAAAGGCAGATGGATCAGCCAAG-3' }\end{array}$ & 65 & 72 \\
\hline NFKB1 & $\begin{array}{l}\text { Forward: 5'-GTGGTGCCTCACTGCTAACT-3' } \\
\text { Reverse: 5'-GGATGCACTTCAGCTTCTGT-3' }\end{array}$ & 58 & 72 \\
\hline NFKB2 & $\begin{array}{l}\text { Forward: 5'-TAGCCACAGAGATGGAGGAG-3' } \\
\text { Reverse: 5'-CCGAGTCGCTATCAGAGGTA-3' }\end{array}$ & 60 & 72 \\
\hline REL & $\begin{array}{l}\text { Forward: 5'-AAAGACTGCAGAGACGGCTA-3' } \\
\text { Reverse: 5'-CTCACCACATTGAGGTCACA-3' }\end{array}$ & 58 & 72 \\
\hline RELA & $\begin{array}{l}\text { Forward: 5'-GCACAGATACCACCAAGACC-3' } \\
\text { Reverse: 5'-TCAGCCTCATAGAAGCCATC-3' }\end{array}$ & 58 & 72 \\
\hline RELB & $\begin{array}{l}\text { Forward: 5'-CATTGAGCGGAAGATTCAAC-3' } \\
\text { Reverse: 5'-GCAGCTCTGATGTGTTTGTG-3' }\end{array}$ & 56 & 72 \\
\hline AR & $\begin{array}{l}\text { Forward: 5'-AAGGCTATGAATGTCAGCCCA-3' } \\
\text { Reverse: 5'-CATTGAGGCTAGAGAGCAAGGC-3' }\end{array}$ & 60 & 72 \\
\hline
\end{tabular}

H3F3A, H3 histone, family 3A; RPLPO, Ribosomal phosphoprotein; NFKB1, nuclear factor- $\kappa$ B subunit 1; NFKB2, nuclear factor- $\kappa$ B subunit 2; REL, REL proto-oncogene nuclear factor- $\kappa B$ subunit; RELA, RELA proto-oncogene nuclear factor- $\kappa \mathrm{B}$ subunit; RELB, RELB proto-oncogene nuclear factor- $\mathrm{\kappa B}$ subunit; $\mathrm{AR}$, androgen receptor.

prostate cancer cells $(6.61 \pm 0.92$; Fig. 1B) presented lower NFKB2 mRNA expression than androgen-independent lines $(10.11 \pm 1.63$ for DU-145 and $49.00 \pm 6.10$ for PC 3 ; Fig. $2 B$, right panel). Furthermore, NFKB1 gene expression is downregulated by both investigated peptide hormones in prostate cancer cells. However, NFKB2 mRNA expression was dependent upon both the line and the peptide (Figs. 1B and 2B). RELA expression was comparable in $\mathrm{LNCaP}(0.66 \pm 0.11$; Fig. $1 \mathrm{C})$ and PC3 (0.54 \pm 0.98 ; Fig. $2 \mathrm{C}$, right panel) cell lines but was

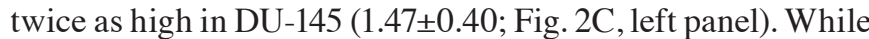
relaxin 2 induces alterations in RELA expression only in PC3 and DU-145 androgen-independent prostate cancer cell lines, Ang II only increases RELA expression in LNCaP and PC3 cells, not in DU-145 (Figs. 1C and 2C). The highest RELB expression was observed in PC3 cells $(9.81 \pm 2.35$; Fig. 1D) and lowest in LNCaP cells $(0.35 \pm 0.10$; Fig. 2D). RELB expression did not significantly change in response to Ang II and RLN2 in any of the cell lines tested (P>0.05; Fig. 2D, both panels). REL expression in LNCaP cells $(0.68 \pm 0.10$; Fig. 1E) was less than half that observed in androgen-independent cells (DU-145, 2.03 \pm 0.41 ; PC3, 1.68 \pm 0.45 ; Fig. 2E). Ang II increases REL mRNA expression in LNCaP and DU-145 cells, but no changes were identified in PC 3 cells in any of the cases examined.

Influence of Ang II and relaxin 2 on $m R N A$ expression of members of the NF- $k B$ transcription factor gene family in the prostatic epithelial cell line. Of all cell lines tested, normal human prostate epithelial cells (PNT1A) demonstrated the highest expression of RELA (1.72 \pm 0.33 ; Fig. 3C), and neither Ang II nor relaxin 2 induced changes in RELA expression in PNT1A cells ( $\mathrm{P}>0.05$; Fig. $3 \mathrm{C})$. In addition, RELB was expressed at a high level in PNT1A cells $(2.88 \pm 0.35$; Fig. 3D) and was observed to be up regulated by both investigated hormones (all $\mathrm{P}<0.05$; Fig. 3D). RELB expression was more than three times higher for Ang II and four times higher for relaxin 2. The expression of NFKB1 $(0.69 \pm 0.15$; Fig. 3A) and REL (1.40 \pm 0.08 ; Fig. 3E) was comparable to the LNCaP cells but lower than in DU-145 and PC3 cell lines. Only relaxin 2 was demonstrated to influence the expression of both REL and NFKB1 in PNT1A, with the expression of NFKB1 being increased two-fold following incubation with relaxin 2, when compared with the control $(\mathrm{P}<0.05 ;$ Fig. 3A). Expression of REL increased 2.5 times, when compared with the control $(\mathrm{P}<0.05$; Fig. 3E). NFKB2 expression was observed in the normal prostate cell line $(8.83 \pm 2.28$; Fig. $3 \mathrm{~B})$, but the mRNA level remained constant regardless of treatment ( $\mathrm{P}>0.05 ;$ Fig. 3B).

\section{Discussion}

Members of the NF- $\kappa \mathrm{B}$ family are important regulators of the signal transduction pathway, and the serve essential roles in a variety of physiological and pathological processes. $\mathrm{NF}-\kappa \mathrm{B}$ activation is known to be associated with inflammation-associated tumor promotion, progression and metastasis in prostate cancer (7-10). The present study compares the changes in NFKB1, NFKB2, RELA, RELB and REL gene expression following exposure to Ang II and relaxin 2 in prostate non-cancerous epithelial (PNT1A), androgen-dependent (LNCaP) and androgen-independent (DU-145, PC3) prostate cancer cell lines. As these cell lines represent various steps of prostate tumor development from disease promotion and early-stage cancer to hormone-refractory disease, their aggressiveness and hormonal status are different $(10,11)$. 
A
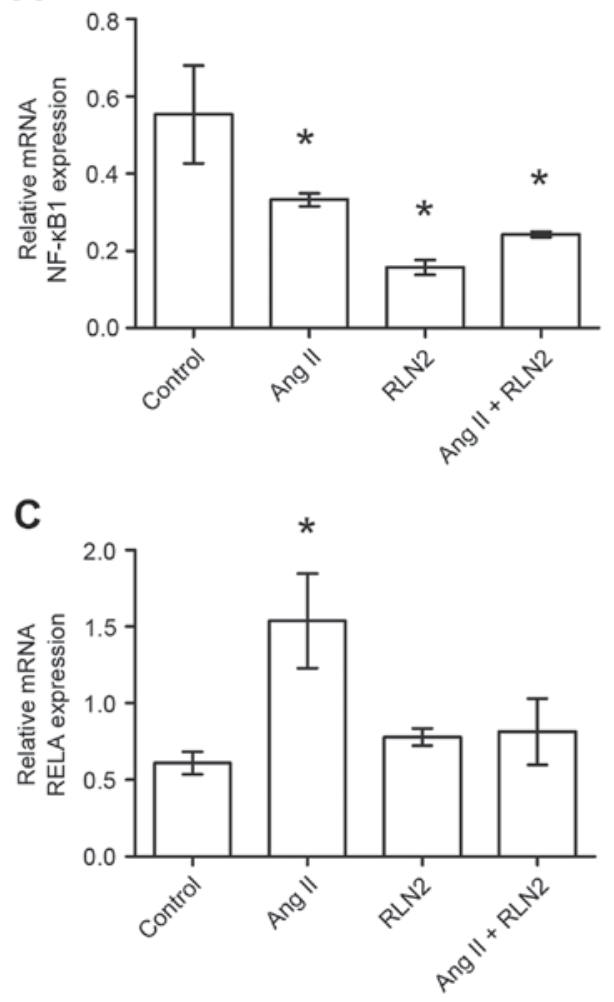

E

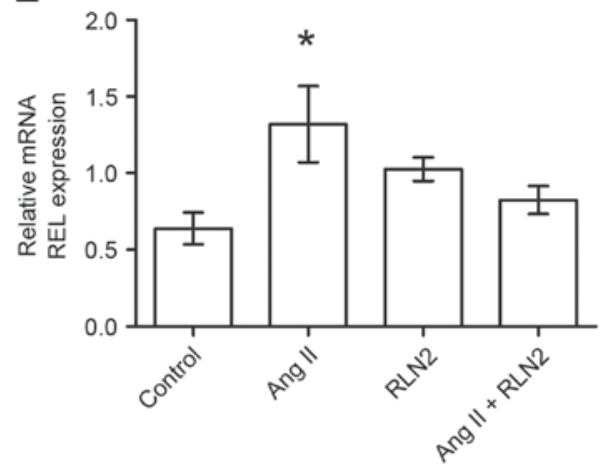

B

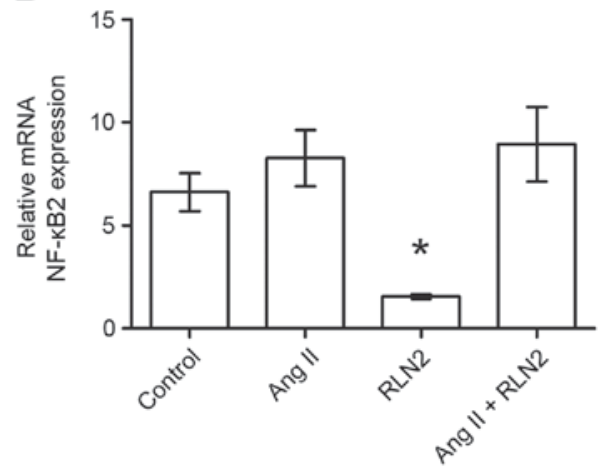

D

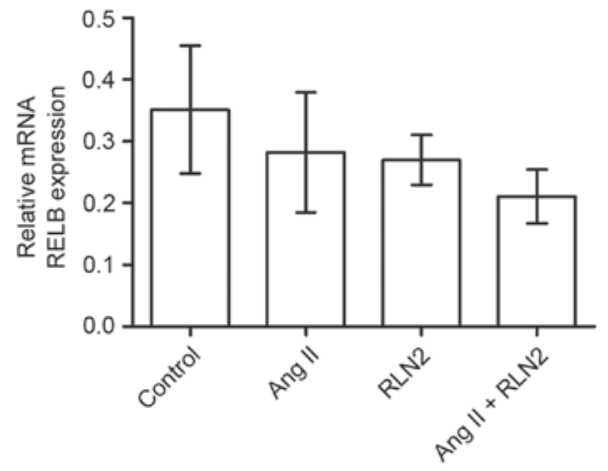

Figure 1. The changes in mRNA expression of (A) NFKB1, (B) NFKB2, (C) RELA, (D) RELB and (E) REL genes in the androgen-dependent prostate cancer cell line LNCaP following exposure to peptide hormones (Ang II, RLN2, Ang II + RLN2). Relative gene expression was calculated based on the Roche guidebook according to a previously published algorithm. H3F3A and RPLPO were used as endogenous controls and Universal Human Reference RNA was used as a calibrator. Data are presented as the mean \pm standard error of the mean $(n \geq 3)$. $P<0.05$ vs. control. NFKB1, nuclear factor- $\kappa B$ subunit 1 ; NFKB2, nuclear factor- $\kappa \mathrm{B}$ subunit 2 ; REL, REL proto-oncogene nuclear factor- $\kappa \mathrm{B}$ subunit; RELA, RELA proto-oncogene nuclear factor- $\kappa \mathrm{B}$ subunit; RELB, RELB

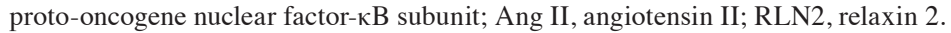

Androgen-independent cell lines, such as DU-145 or PC-3, constitutively express high levels of NF-kB, while androgen-dependent cell lines, for example LNCaP and normal human prostate epithelial cells, demonstrate only low NF-kB gene activation $(9,15)$. These results are in line with those obtained in the authors studies for NFKB1 and NFKB2. RT-qPCR indicated that the relative expression of both NFKB genes was the highest for PC3 cells and the lowest for LNCaP cells. Similarly, Suh et al (16) noted that only prostate cell lines with low NF-kB activity express endogenous AR, and suggest that the $\mathrm{AR}$ and $\mathrm{NF}-\kappa \mathrm{B}$ are inversely related; the loss of $\mathrm{AR}$ is accompanied by an increase in NF- $\mathrm{B}$ activity. It seems that constitutive activation of NF-kB may contribute to compensatory cellular changes allowing cell survival and growth in the absence of AR activation (16). Earlier findings of the authors indicate that AR levels are $>30$ times higher in LNCaP cells than in PC3 cells (6). Alimirah et al (17) report that AR mRNA levels were $50 \%$ lower in DU-145 cells than in LNCaP cells, and that AR expression is much lower in PC3 cells than in both DU-145 and LNCaP cells (17).

No differences in NFKB1 level were observed between the androgen-independent cell lines, regardless of AR expression. However, a significantly higher level of NFKB2 gene expression was observed in the $\mathrm{PC} 3$ cell line than in the less aggressive DU-145. A similar situation was found in PNT1A cells; the prostatic epithelial cell line and the LNCaP cells demonstrated comparable NFKB1 expression, and Bidaux et al (18) report that AR expression is far lower in PNT1A than LNCaP. In this case, NFKB2 mRNA expression was also higher in the non-cancerous than the $\mathrm{LNCaP}$ cell line. Therefore, the authors 

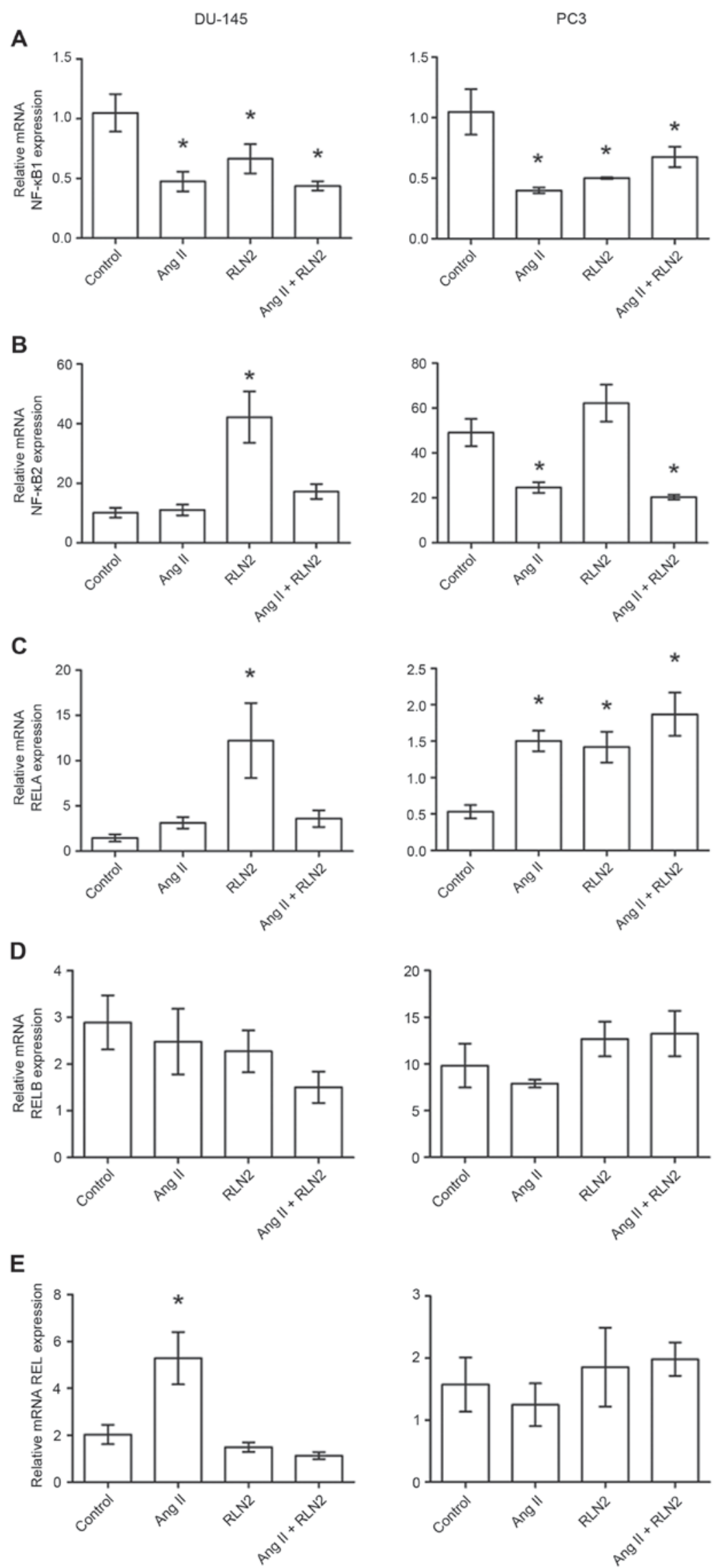

Figure 2. The changes in mRNA expression of (A) NFKB1, (B) NFKB2, (C) RELA, (D) RELB and (E) REL genes in androgen-independent prostate cancer cell lines DU-145 and PC3 following exposure to peptide hormones (Ang II, RLN2, Ang II + RLN2). Relative gene expression was calculated based on the Roche guidebook according to a previously published algorithm. H3F3A and RPLPO were used as endogenous controls and Universal Human Reference RNA was used as a calibrator. Data are presented as the mean \pm standard error of the mean $(n \geq 3)$. "P $<0.05$ vs. control. NFKB1, nuclear factor- $\kappa B$ subunit 1 ; NFKB2, nuclear factor- $\mathrm{kB}$ subunit 2; REL, REL proto-oncogene nuclear factor- $\mathrm{\kappa B}$ subunit; RELA, RELA proto-oncogene nuclear factor- $\mathrm{KB}$ subunit; RELB, RELB proto-oncogene nuclear factor-kB subunit; Ang II, angiotensin II; RLN2, relaxin 2. 
A

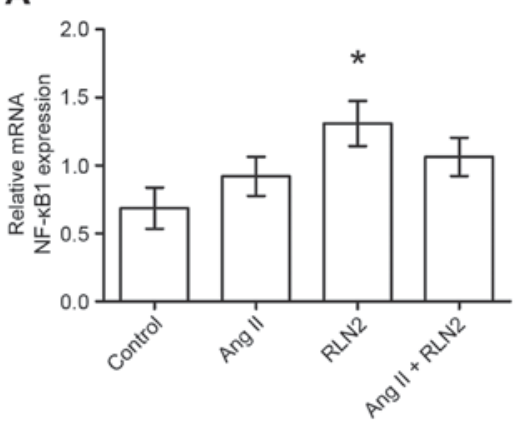

C

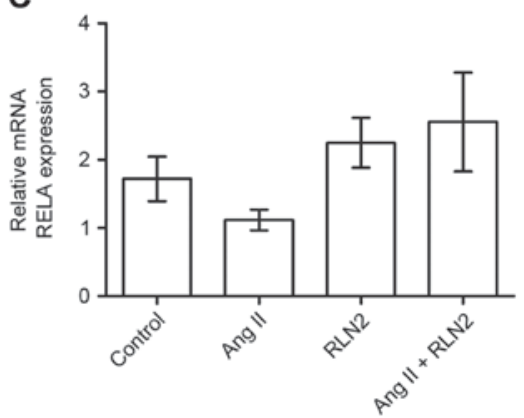

E

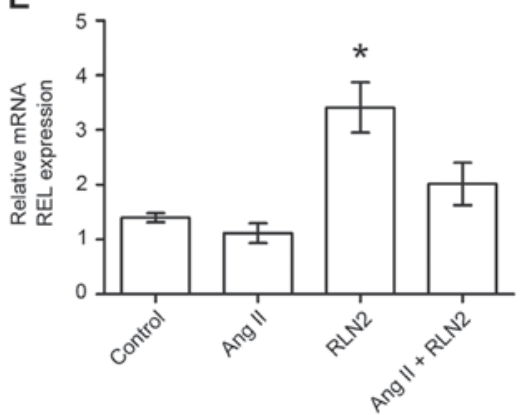

B

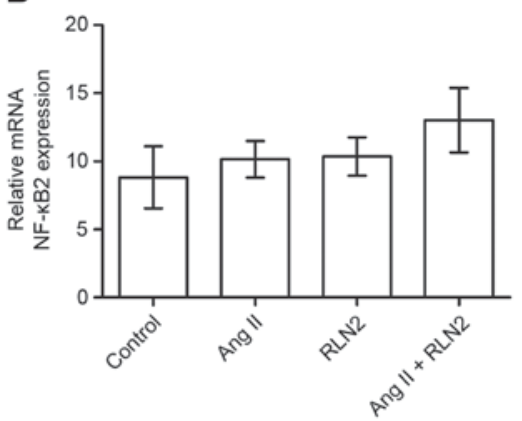

D

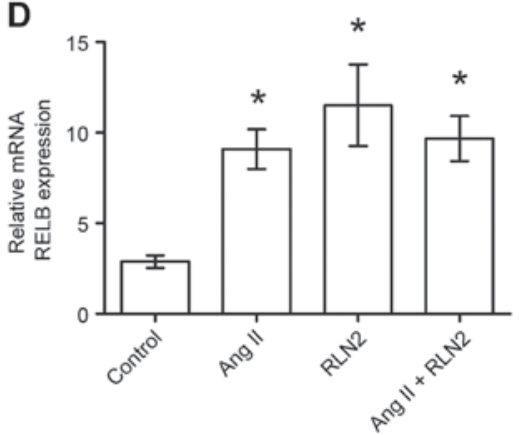

Figure 3. The changes in mRNA expression of (A) NFKB1, (B) NFKB2, (C) RELA, (D) RELB and (E) REL genes in non-cancerous prostate epithelial cells (PNT1A) following exposure to peptide hormones (Ang II, RLN2, Ang II + RLN2). Relative gene expression was calculated based on the Roche guidebook according to a previously published algorithm. H3F3A and RPLPO were used as endogenous controls and Universal Human Reference RNA was used as a calibrator. Data are presented as the mean \pm standard error of the mean $(n \geq 3)$. ${ }^{*}<0.05$ vs. control. NFKB1, nuclear factor- $\kappa B$ subunit 1 ; NFKB2, nuclear factor- $\kappa B$ subunit 2; REL, REL proto-oncogene nuclear factor- $\kappa \mathrm{B}$ subunit; RELA, RELA proto-oncogene nuclear factor- $\kappa \mathrm{B}$ subunit; RELB, RELB proto-oncogene nuclear factor- $\kappa \mathrm{B}$ subunit; Ang II, angiotensin II; RLN2, relaxin 2.

speculate that the level of NFKB2 mRNA, but not NFKB1, in prostate cells may be closely linked to AR expression.

The NFKB1 gene maps on chromosome 4q24 and encodes protein p105/p50, while the NFKB2 gene maps on chromosome $10 \mathrm{q} 24$ and encodes protein $\mathrm{p} 100 / \mathrm{p} 52$. Both proteins may promote cell survival through the induction of target genes, whose products directly or indirectly regulate the apoptotic machinery in normal and cancerous cells (10). The noncanonical $\mathrm{NF}-\kappa \mathrm{B}$ signaling pathway mediates the activation of $\mathrm{p} 52 / \mathrm{RelB}$, whereas thecanonicalpathway mediates theactivationof $50 / \mathrm{p} 65$. Previous work has indicated that several interconnections between classic and alternative $\mathrm{NF}-\kappa \mathrm{B}$ pathways exist and these may be essential in various biological processes (19). Earlier studies of the authors note that the RAS and RFPS influence the growth, division and spread of prostate cancer cells to some degree via overlapping signal transduction pathways (6). It is possible that members of the NF- $\kappa \mathrm{B}$ transcription factor gene family could serve an important role in this case. The current findings indicated that Ang II and relaxin 2 may modulate the mRNA expression of nuclear factor $\kappa \mathrm{B}$ genes in prostate cells.

One of our most interesting observations is that Ang II and relaxin 2 significantly decrease the expression of NFKB1 mRNA in all cancer cell lines, yet they increase it in normal epithelial cells. However, in PNT1A cells, the results were statistically significant only for relaxin 2 . In addition, relaxin 2 radically increased the levels of androgen receptors in this cell line, reaching levels more than five times above baseline (data not shown). A dual increase of AR and NFKB1 expression may be required to promote prostate carcinogenesis. The expression of NFKB2 in normal epithelial prostate cells is not altered by peptide hormones.

The mechanism underlying the downregulation of NFKB1 expression by both peptide hormones in prostate cancer cells is not an obvious one, and further research is needed to clarify it. Setlur et al (20) demonstrated that the expression of NFKB1 is upregulated in localized prostate cancer and hormone-naïve metastasis, but downregulated in hormone-refractory 
metastasis. In contrast, metastatic samples demonstrated greater nuclear localization of NFKB1, which may be mediated by low levels of the NF- $\kappa \mathrm{B}$ inhibitor, I $\kappa \mathrm{B} \alpha(20)$. Nevertheless, all findings suggested that NFKB1 expression is important for the early development of prostate cancers and for advanced disease. Differences in NF- $\kappa \mathrm{B}$ activity between androgen-sensitive and androgen-independent prostate cancer cell lines may contribute to androgen autonomy (21).

The RELB gene maps on chromosome 19q13.32 and encodes protein $\mathrm{p} 66$, which regulates the migration and invasion abilities of cancer cells. High constitutive nuclear levels of RelB have been observed in human prostate cancer specimens with high Gleason scores $(19,22)$. Furthermore, increased levels of RelB enhanced prostate cancer cell survival rate after treatments and contributes to the resistance of PCa cells to radiation (19).

Josson et al (23) identified that RelB nuclear localization is significantly higher in the aggressive PC-3 prostate cancer cell line than in the less aggressive $\mathrm{LNCaP}$ cell line. In the present study, the expression of RELB mRNA in prostate cancer cells was the highest for PC3, indirect for DU-145 and the lowest for LNCaP. Surprisingly, the levels of RELB mRNA were higher in the non-tumorigenic PNT1A cell line than in the poorly tumorigenic androgen-dependent prostate cancer cell line. Hatano et al (24) report that the levels of RelB were higher in normal prostate epithelial cells (PNT2) than in LNCaP cells when cells or cytoplasmic extracts were used. However, when nucleus extract was used, RelA and RelB expression was much higher in prostate cancer cells, PC3, DU-145 and LNCaP than in normal prostate epithelial cells (PNT2) (24).

$\mathrm{Xu}$ et al (19) observed that LNCaP cell tumorigenicity was enhanced following RelB overexpression, while PC-3 cell tumorigenicity was attenuated by RelB knockdown. Wang et al (25) indicated that RelB knockdown significantly suppresses the migration and invasion of DU-145 prostate cancer cells. The authors' previous findings confirm that both peptide hormones can promote the invasion and spread of human prostate cells via up-regulation of MMPs $(5,6)$. In addition, $\mathrm{NF}-\kappa \mathrm{B}$ can stimulate aggressiveness by regulating the expression of various matrix metalloproteinases, especially MMP-2 and MMP-9 (7,8). Unexpectedly, Ang II and relaxin 2 significantly enhanced mRNA expression of RELB only in normal epithelial cells. Therefore, it appears that both peptide hormones can contribute to the initiation of prostate cancer by the $N F-\kappa B$ alternative pathway. It is worth noting that the level of RELB mRNA expression may not reflect the nuclear levels of RelB. Further studies are required in order to conclude a causal association between RelB and cancer progression following Ang II or relaxin 2 induction.

The RELA gene maps on chromosome 11q13 and encodes the protein p65, which regulates the transcription of a wide variety of genes involved in cell survival, invasion and metastasis (26). Nuclear expression of RelA is specific to prostate cancers and related to a poor outcome for prostate cancer patients, however the RELA gene is not associated with the Gleason score $(26,27)$. The level of RELA mRNA presented no relation to the aggressiveness of the tested prostate cancer cells.

Interestingly, Palvimo et al (28) note that elevated expression of RelA repressed AR-mediated transactivation in a dose-dependent manner. Co-immunoprecipitation and protein-protein interaction assays did not detect any specific association between AR and RelA. However, it was demonstrated that repression by RelA could not be overcome by the addition of excess AR. These results suggested that the two proteins competed for the coactivator(s) present in limiting amounts in the cell, or that RelA induces the expression of an unknown repressor of AR (28). Nelius et al (29) report that AR (+) PC-3 cells became less tumorigenic on an ambient testosterone background than AR (-) PC-3. AR expression was identified to lower the mRNA and protein levels of RelA, and reduce the activity and nuclear localization of p65. Previous studies of the authors indicate a decrease in AR expression in PC3 cells treated with the peptide hormones, but the results were insignificant. The present findings indicated that, while both peptide hormones increase mRNA expression of RELA in the androgen-independent prostate cancer cell line PC3, these relationships were not observed for the non-cancerous prostate epithelial cell line. Neither Ang II nor relaxin 2 altered the level of RELA inPNT1A, regardless of any significant reduction in AR expression.

The REL gene maps on chromosome 12p12 and encodes protein $\mathrm{p} 75$, which is associated with the malignant progression of solid tumors such as breast cancer, gastric and pancreatic cancer (30-32). For example, breast tumors present increased expression of mRNA for c-Rel, as well as for other NF-kB family members, compared to non-tumorigenic adjacent tissue (32). In the present study, Ang II was indicated to increase the expression of REL gene mRNA in prostate cancer cells, with the exception of the most aggressive line (PC3), whereas relaxin 2 only influenced normal prostate epithelial cells. Interestingly, Mukhopadhyay et al (33) report that c-Rel, similar to AR, is a component of the nucleoprotein complex regulating the androgen-responsive prostate-specific antigen (PSA) promoter. Moreover, an analysis of the AR and c-Rel protein levels demonstrated that promoter downregulation was not attributable to mutual decreases in the quantity of AR or c-Rel. It is worth remembering that DU-145 and PC-3 do not express PSA.

Based on some of the authors' earlier works and other recent studies, we postulate that both Ang II and relaxin 2 have an impact on the proliferation or invasion of prostate cells via canonical and non-canonical NF-kB pathways. The present results indicated significant differences between the regulation of the expression of NFKB1, NFKB2, RELA, RELB and REL mRNA in non-cancerous epithelial, androgen-dependent and androgen-independent prostate cancer cells by both peptide hormones. Undoubtedly, further studies are required in order to examine the interaction between the members of the NF- $\kappa \mathrm{B}$ transcription factor gene family and AR. Nevertheless, it seems that the RAS and RFPS can serve an important role in the regulation of both.

\section{Acknowledgements}

This work was supported by Ministry of Science and Higher Education grant NN 403208139 and Medical University of Lodz grant 503/0-078-04/503-01-001.

\section{References}

1. Domińska K: Relaxin 2-a pregnancy hormone involved in the process of carcinogenesis. Ginekol Pol 84: 126-130, 2013. 
2. Domińska K and Lachowicz-Ochedalska A: The involvement of the renin-angiotensin system (RAS) in cancerogenesis. Postepy Biochem 54: 294-300, 2008 (In Polish).

3. Wegman-Ostrosky T, Soto-Reyes E, Vidal-Millán S and Sánchez-Corona J: The renin-angiotensin system meets the hallmarks of cancer. J Renin angiotensin Aldosterone Syst 16: 227-233, 2015.

4. Nair VB, Samuel CS, Separovic F, Hossain MA and Wade JD: Human relaxin-2: Historical perspectives and role in cancer biology. Amino Acids 43: 1131-1140, 2012.

5. DomińskaK,Ochędalski T,KowalskaK,Matysiak-BurzyńskaZE, Płuciennik E and Piastowska-Ciesielska AW: A common effect of angiotensin II and relaxin 2 on the PNT1A normal prostate epithelial cell line. J Physiol Biochem 72: 381-392, 2016.

6. DomińskaK,Ochedalski T,KowalskaK,Matysiak-BurzyńskaZE, Płuciennik E and Piastowska-Ciesielska AW: Interaction between angiotensin II and relaxin 2 in the progress of growth and spread of prostate cancer cells. Int J Oncol 48: 2619-2628, 2016.

7. Jin R, Sterling JA, Edwards JR, DeGraff DJ, Lee C, Park SI and Matusik RJ: Activation of NF-kappa B signaling promotes growth of prostate cancer cells in bone. PLoS One 8: e60983, 2013.

8. Hoesel B and Schmid JA: The complexity of NF- $\kappa$ B signaling in inflammation and cancer. Mol Cancer 12: 86, 2013.

9. Nguyen DP, Li J, Yadav SS and Tewari AK: Recent insights into $\mathrm{NF}-\mathrm{KB}$ signalling pathways and the link between inflammation and prostate cancer. BJU Int 114: 168-176, 2014.

10. Luo JL, Kamata $H$ and Karin $M$ : IKK/NF- $\kappa B$ signaling: Balancing life and death-a new approach to cancer therapy. J Clin Invest 115: 2625-2632, 2005.

11. Wu X, Gong S, Roy-Burman P, Lee P and Culig Z: Current mouse and cell models in prostate cancer research. Endocr Relat Cancer 20: R155-R170, 2013.

12. Avancès C, Georget V, Térouanne B, Orio F, Cussenot O, Mottet N, Costa P and Sultan C: Human prostatic cell line PNT1A, a useful tool for studying androgen receptor transcriptional activity and its differential subnuclear localization in the presence of androgens and antiandrogens. Mol Cell Endocrinol 184: 13-24, 2001

13. Dominska K, Piastowska-Ciesielska AW, Pluciennik E, Lachowicz-Ochedalska A and Ochedalski T: A comparison of the effects of angiotensin IV on androgen-dependent and androgen-independent prostate cancer cell lines. J Renin angiotensin Aldosterone Syst 14: 74-81, 2013.

14. Pfaffl MW, Horgan GW and Dempfle L: Relative expression soft-ware tool (REST) for group-wise comparison and statistical analysis of relative expression results in real-time PCR. Nucleic Acids Res 30: e36, 2002.

15. Gasparian AV, Yao YJ, Kowalczyk D, Lyakh LA, Karseladze A Slaga TJ and Budunova IV: The role of IKK in constitutive activation of NF-kappa B transcription factor in prostate carcinoma cells. J Cell Sci 115: 141-151, 2002.

16. Suh J,Payvandi F, Edelstein LC, Amenta PS,Zong WX, Gélinas C and Rabson AB: Mechanisms of constitutive NF-kappa B activation in human prostate cancer cells. Prostate 52: 183-200, 2002.

17. Alimirah F, Chen J, Basrawala Z, Xin H and Choubey D: DU-145 and PC-3 human prostate cancer cell lines express androgen receptor: Implications for the androgen receptor functions and regulation. FEBS Lett 580: 2294-2300, 2006.

18. Bidaux G, Roudbaraki M, Merle C, Crépin A, Delcourt P, Slomianny $\mathrm{C}$, Thebault S, Bonnal JL, Benahmed M Cabon F, et al: Evidence for specific TRPM8 expression in human prostate secretory epithelial cells: Functional androgen receptor requirement. Endocr Relat Cancer 12: 367-382, 2005.

19. Xu Y, Josson S, Fang F, Oberley TD, St Clair DK, Wan XS, Sun Y, Bakthavatchalu V, Muthuswamy A and St Clair WH: RelB enhances prostate cancer growth: Implications for the role of the nuclear factor-kappaB alternative pathway in tumorigenicity. Cancer Res 69: 3267-3271, 2009.
20. Setlur SR, Royce TE, Sboner A, Mosquera JM, Demichelis F, Hofer MD, Mertz KD, Gerstein M and Rubin MA: Integrative microarray analysis of pathways dysregulated in metastatic prostate cancer. Cancer Res 67: 10296-10303, 2007.

21. Altuwaijri S, Lin HK, Chuang KH, Lin WJ, Yeh S, Hanchett LA, Rahman MM, Kang HY, Tsai MY, Zhang Y, et al: Interruption of nuclear factor kappaB signaling by the androgen receptor facilitates 12-O-tetradecanoylphorbolacetate-induced apoptosis in androgen-sensitive prostate cancer LNCaP cells. Cancer Res 63: 7106-7112, 2003

22. Lessard L, Bégin LR, Gleave ME, Mes-Masson AM and Saad F: Nuclear localisation of nuclear factor-kappa B transcription factors in prostate cancer: An immunohistochemical study. Br J Cancer 93: 1019-1023, 2005.

23. Josson S, Xu Y, Fang F, Dhar SK, St Clair DK and St Clair WH: RelB regulates manganese superoxide dismutase gene and resistance to ionizing radiation of prostate cancer cells. Oncogene 25: $1554-1559,2006$

24. Hatano K, Miyamoto Y, Nonomura N and Kaneda Y: Expression of gangliosides, GD1a, and sialyl paragloboside is regulated by $N F-\kappa B$-dependent transcriptional control of $\alpha 2,3$-sialyltransferase I, II and VI in human castration-resistant prostate cancer cells. Int J Cancer 129: 1838-1847, 2011.

25. Wang J, Yi S, Zhou J, Zhang Y and Guo F: The NF-кB subunit RelB regulates the migration and invasion abilities and the radio-sensitivity of prostate cancer cells. Int J Oncol 49: 381-392, 2016.

26. Domingo-Domenech J, Mellado B, Ferrer B, Truan D, Codony-Servat J, Sauleda S, Alcover J, Campo E, Gascon P, Rovira A, et al: Activation of nuclearfactor-kappaB in human prostate carcinogenesis and association to biochemical relapse. Br J Cancer 93: 1285-1294, 2005.

27. Seo SI, Song SY, Kang MR, Kim MS, Oh JE, Kim YR, Lee JY, Yoo NJ and Lee SH: Immunohistochemical analysis of NF-kappaB signaling proteins IKK epsilon, p50/p105, p52/p100 and RelA in prostate cancers. APMIS 117: 623-628, 2009.

28. Palvimo JJ, Reinikainen P, Ikonen T, Kallio PJ, Moilanen A and Jänne OA: Mutual transcriptional interference between RelA and androgen receptor. J Biol Chem 271: 24151-24156, 1996

29. Nelius T, Filleur S, Yemelyanov A, Budunova I, Shroff E, Mirochnik Y, Aurora A, Veliceasa D, Xiao W, Wang Z and Volpert OV: Androgen receptor targets NFkappaB and TSP1 to suppress prostate tumor growth in vivo. Int J Cancer 121: 999-1008, 2007.

30. Hunter JE, Leslie J and Perkins ND: c-Rel and its manyroles in cancer: An oldstory with new twists. Br J Cancer 114: 1-6, 2016.

31. Weichert W, Boehm M, Gekeler V, Bahra M, Langrehr J, Neuhaus P, Denkert C, Imre G, Weller C, Hofmann HP, et al: Highexpression of RelA/p65 is associated with activation of nuclear factor-kappaB-dependent signaling in pancreatic cancer and marks a patient population with poor prognosis. Br J Cancer 97: 523-530, 2007.

32. Sarkar DK, Jana D, Patil PS, Chaudhari KS, Chattopadhyay BK, Chikkala BR, Mandal S and Chowdhary P: Role of NF-kB as a prognostic marker in breast cancer: A pilot study in Indian patients. Indian J Surg Oncol 4: 242-247, 2013.

33. Mukhopadhyay NK, Ferdinand AS, Mukhopadhyay L, Cinar B, Lutchman M, Richie JP, Freeman MR and Liu BC: Unraveling androgen receptor interactomes by an array-based method: discovery of proto-oncoprotein c-Rel as a negative regulator of androgen receptor. Exp Cell Res 312: 3782-3795, 2006. 